\title{
Enteric Dissolution Enhancement of Engineered Gastro Resistant Omeprazole Tablets using Hydroxypropyl Methylcellulose Acetate Succinate
}

\author{
Sagar Kumar Mohapatra1, Rudra Narayan Sahoo ${ }^{1,2}$, Subrata Mallick', Rajaram Mohapatra',* \\ 'Department of Pharmaceutics, School of Pharmaceutical Sciences, Siksha 'O' Anusandhan (Deemed to be University), Bhubaneswar, \\ Odisha, INDIA. \\ ${ }^{2}$ School of Pharmacy and Life Sciences, Centurion University of Technology and Management, Odisha, INDIA.
}

\begin{abstract}
Purpose: Oral drug delivery system has always been a preferred choice for the treatment of peptic ulcer and gastroesophageal reflux diseases. Being a proton pump inhibitor omeprazole restricts gastric acid secretion but the foremost downside is its degradation in acidic environments. The systemic absorption of gastro-unstable drugs can be improved by the enteric coating. Materials and Methods: This study was aimed at developing an effective enteric coating for omeprazole tablets using HPMC E5-LV and Hydroxypropyl Methylcellulose Acetate Succinate (HPMC-AS) polymers. The core tablets were subcoated with HPMC E5-LV which acted as a barrier between core tablet and enteric coated tablet. The enteric coating was applied using HPMC-AS. Results: Dissolution information unveiled that the enteric coat remained in place for $2 \mathrm{hr}$ in acidic medium $(0.1 \mathrm{~N} \mathrm{HCl}$ ) and later dissolved when came in contact with basic media (acetate buffer $\mathrm{pH}$ 6.8), it dissolved within a jiffy. Conclusion: The release profile showed 91 to $98 \%$ drug release within $1 \mathrm{hr}$ in $\mathrm{pH} 6.8$ Acetate buffer. Further instrumental analysis was performed to ascertain drug-polymer interaction.
\end{abstract}

Key words: Proton pump inhibitor, Enteric coating, HPMC, Omeprazole, Dissolution enhancement.

\section{INTRODUCTION}

The first "Proton Pump Inhibitor (PPI)" Omeprazole, is one of the major active ingredient in antiulcerative drug products, extensively used for prevention and treatment of gastric and duodenal ulcers, symptomatic gastro-esophageal reflux, ${ }^{1}$ gastric bleeding ${ }^{2}$ and dyspepsia. ${ }^{3}$ The omeprazole drug product is kenned to degrade in acidic media as a function of $\mathrm{pH}$ but has acceptable stability under alkaline conditions. ${ }^{4}$ The PPI irreversibly blocks the parietal proton pump of the gastric mucosa. ${ }^{5,6}$ This ion gated pump is responsible for eluting protons into the gastric environment. Inhibition of the pump result in lowering of overall acid secretion by gastric mucosa. ${ }^{7,8}$ Decrementing acid can lead to the rejuvenation of duodenal ulcers and provide relief.
In the delayed release tabet the dosage form is relinquished after certain time interval so that it can pass through the upper GI and reach the intestine. To achieve this goal the dosage form is often coated with a polymer which acts as a barrier and prevents drug dissolution in acidic $\mathrm{pH} .{ }^{9}$ Enteric coating also acts a mean to barricade the drugs from degradation which are unstable in the gastric environment. Enteric coating is additionally an efficacious method to obtain drug targeting (such as gastro-resistant drugs). The enteric coated tablet formulations are considered as delayed action delivery systems. Omeprazole is acid-labile and decomposes rather rapidly at $\mathrm{pH}<5 .{ }^{10}$ Polymers like hydroxypropylmethylcellulose, hydroxypropylmethylcellulose phthalate, cellulose acetate
Submission Date: 26-02-2021; Revision Date: 10-04-2021; Accepted Date: 02-07-2021

DOI: 10.5530/ijper.55.3.139 Correspondence: Dr. Rajaram Mohapatra Assistant Professor, Department of Pharmaceutics, School of Pharmaceutical Sciences, Siksha 'O' Anusandhan, (Deemed to be University), Bhubaneswar-751003, Odisha, INDIA. Phone no: +91 674-2386209 Email: rajaram.liku@gmail.com

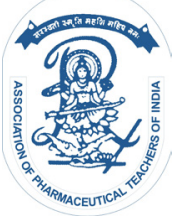

www.ijper.org 
phthalate, polyvinylacetate phthalate, methylmethacrylate are commonly utilized in enteric coating. ${ }^{11}$ HPMC-AS is a semi synthetic compound prepared by addition of hydrophobic acetate group and ionizable succinic acid group to the hydrophilic hydroxyl groups of the HPMC backbone. This change in chemistry results in increased inherent lipophilicity and $\mathrm{pH}$ specific solubility which was not previously native to the polymer. This modification makes HPMC-AS an unique enteric coating candidate over its contemporaries. ${ }^{12}$

Several attempts were made to increase the bio-availabilty of omeprazole. Choi et al. 2000 prepared bucco-adhesive omeprazole tablets using HPMC to bypass Hepatic fast-pass metabolism and gastric degradation but disadvantages like low permeability, ${ }^{13}$ small absorption area, chances of swallowing and the effect of salivary scavenging make it a less preferable formulatory approach. Tu "rkoglu et al. 2004 prepared enteric-coated omeprazole pellets employing microcrystalline cellulose as an aid in plastic deformation in the compression process. ${ }^{14}$ Though microcrystalline cellulose enhanced the compressiblility of omeprazole, variation in it's concerntration played a key role in the degradation of drug itself in acidic medium. Choudhury et al. 2010 prepared omeprazole mucoadhesive tablets containing $20 \mathrm{mg}$ omeprazole coated with carbopol 934P achieved satisfactory $\%$ swelling index, ${ }^{15}$ drug content and promising mucoadhesive strength, appears to be a potential candidate for the development of mucoadhesive tablet for effective therapeutic use as well as controlled drug delivery but with some disadvantages like drug loss during coating. The presnt research is aimed at a stable omeprazole oral formulation by taking HPMC AS as enteric coating material due to it's contribution in enhancing dissolution and stability. ${ }^{16}$

\section{MATERIALS AND METHODS}

\section{Materials}

All the Materials employed for the development of omeprazole enteric coated tablets were, Omeprazole (Aurobindo Pharma), Lactose Monohydrate (DFE Pharma), Sodium Starch Glycolate(SSG) (DMV), Sodium Steryl Fumarate(SSF) (JRS Pharma), Methocel E5 premium LV (The DOW Chemical), Sodium Lauryl Sulfate (SLS) (BASF), Sodium Hydroxide Pellets (Rankem), Polyethylene Glycol 6000 (PEG 6000) (Clariant Chemicals), Hydroxy Propyl Methyl Cellulose Aetate Succinate (HPMC AS) (Ashland), Triethyl Citrate (TEC) (Vertellus), Ammonia Solution (Merck), Talc Ultra Micronized (Imerys Talc Austra) and
Opadry Brown (Colorcon). All the other ingredients used were of analytical grade

\section{Methods}

\section{Preparation of core tablets}

Omeprazole delayed release tablets were prepared by wet granulation method. ${ }^{17}$ All the material were accurately weighed and co-sifted through 30 mesh. The material was loaded into RMG (model-HSMG-2, Gansons) and dry mixed for 10 min with impeller at low speed and chopper off. Dry mix material was checked for LOD (Loss on drying) in Moisture Balance (model-MX 50 AND) at $105^{\circ} \mathrm{C}: 0.85 \%$. Binder solution was prepared by using HPMC E5 LV, $\mathrm{NaOH}$ and sodium stearate. The binder solution was added to the dry mix materials for $2 \mathrm{~min} 30 \mathrm{sec}$ under slow impeller and fast chopper. Further kneading was carried out for $15 \mathrm{sec}$ under slow impeller and slow chopper.

Wet mass was dried at $50^{\circ} \mathrm{C}$ for $30 \mathrm{~min}$ at fluidization 25 to 30 CFM (Cubic Feet per Minute) in rapid dryer (model-TG100, Retsch). Dried granules were checked for LOD at $105^{\circ} \mathrm{C}$ i.e. $0.90 \%$. Dried granules were sifted through 30 mesh. The retained granules were co-milled (model-U5 0280, Quadro) at slow speed and again passed through 30 mesh and all the materials were mixed properly. In prelubrication stage, extra granular materials excepts sodium stearyl fumarate were sifted through 30 mesh and blended in blender (VB 3/5/10, San) with intragranular materials for $10 \mathrm{~min}$ in low shear blender at $16 \mathrm{rpm}$. Sodium stearyl fumarate was shifted through 30 mesh and blended with pre lubrication materials for $5 \mathrm{~min}$ in the low shear blender. Lubricated blend was compressed in compression machine (model-CMD 4, Cadmach) into tablets with the following tooling and parameters i.e. $12.0 \times 6.0 \mathrm{~mm}$ length, Capsule shape, Plain on both side. Formulation of different core trial tablets is depicted in Table 1.

All trial batches were evaluated basing on the physicochemical parameters like weight wariation, friability and disintegration time as per USP guidelines. The batch which showed promising results in physicochemical characterizations was selected for further study.

\section{Sub coating of core tablets}

Sodium hydroxide and PEG 6000 were dissolved in purified water under stirring. HPMC E5 LV was further added slowly to the solution with constant stirring to urge clear solution. Talc UM was added to the above solution under stirring for $20 \mathrm{~min}$. The sub coating solutions were prepared in different concentrations i.e $2.5 \%, 5 \%$ and $7.5 \%$ of coating (Table 2 ). 
Table 1: Formulation for omeprazole core tablets.

\begin{tabular}{|c|c|c|c|c|c|c|c|}
\hline & Trial 1 & Trial 2 & Trial 3 & Trial 4 & Trial 5 & Trial 6 & Trial 7 \\
\hline Ingredients & Mg/tab & Mg/tab & Mg/tab & Mg/tab & Mg/tab & Mg/tab & Mg/tab \\
\hline Omeprazole & 20.08 & 20.08 & 20.08 & 20.08 & 20.08 & 20.08 & 20.08 \\
\hline Lactose Monohydrate & 202.52 & 195.62 & 201.37 & 197.92 & 201.37 & 197.92 & 200.22 \\
\hline Sodium Starch Glycolate & 2.3 & 9.2 & 4.6 & 4.6 & 4.6 & 4.6 & 4.6 \\
\hline Hypromellose E5 LV & 2.3 & 2.3 & 2.3 & 2.3 & 1.15 & 4.6 & 2.3 \\
\hline Sodium Steryl Fumarate & 2.3 & 2.3 & 1.15 & 4.6 & 2.3 & 2.3 & 2.3 \\
\hline NaOH & 0.5 & 0.5 & 0.5 & 0.5 & 0.5 & 0.5 & 0.5 \\
\hline Core tablet weight & 230 & 230 & 230 & 230 & 230 & 230 & 230 \\
\hline
\end{tabular}

\begin{tabular}{|c|c|c|c|}
\hline \multicolumn{4}{|c|}{ Table 2: Formulation of sub coating solution. } \\
\hline & $\begin{array}{c}\text { Batch } \\
\mathbf{1 ( 2 . 5 \% )}\end{array}$ & $\begin{array}{c}\text { Batch } \\
\mathbf{2 ( 5 \% )}\end{array}$ & $\begin{array}{c}\text { Batch } \\
\mathbf{3 ( 7 . 5 0 \% )}\end{array}$ \\
\hline Ingredients & $\mathbf{M g / t a b}$ & $\mathbf{M g} / \mathrm{tab}$ & $\mathbf{M g} / \mathrm{tab}$ \\
\hline Hypromellose E5 LV & 4.60 & 9.20 & 13.79 \\
\hline PEG 6000 & 0.46 & 0.92 & 1.38 \\
\hline Talc UM & 0.63 & 1.27 & 1.90 \\
\hline $\mathrm{NaOH}$ & 0.060 & 0.12 & 0.18 \\
\hline
\end{tabular}

\begin{tabular}{|c|c|c|}
\hline \multicolumn{3}{|c|}{ Table 3: Parameters of coating. } \\
\hline SI. No. & Parameters & Data \\
\hline 1 & Inlet Temperature $\left({ }^{\circ} \mathrm{C}\right)$ & $44-47$ \\
\hline 2 & Exhaust Temperature $\left({ }^{\circ} \mathrm{C}\right)$ & $39-41$ \\
\hline 3 & Bed Temperature $\left({ }^{\circ} \mathrm{C}\right)$ & $37-41$ \\
\hline 4 & Pan RPM & $8-12$ \\
\hline 5 & Spray Pump RPM & $4-6$ \\
\hline 6 & Atomization & bar-1.6 bar \\
\hline
\end{tabular}

Core tablets were loaded into the coating machine (model-GAC 250/375, Ganson) and pre warmed at an inlet temperature $45^{\circ} \mathrm{C}$ with an intermittent inching for $10 \mathrm{~min}$. Sub coating dispersion was sprayed onto pre warmed core tablets with parameters mentioned in Table 3.

\section{Enteric coating sub coated tablets}

Sodium lauryl Sulfate was dissolved in purified water under stirring. Triethyl citrate was integrated to solution with constant stirring. Further HPMC AS was integrated gradually to solution under stirring for 15 min. Liquid ammonia solution was added to adjust the $\mathrm{pH}$ between 7 to 9 . Micronized talc was added slowly to solution under stirring for another $15 \mathrm{~min}$. Lastly Opadry Brown was added to the above mixture and stirring was continued for another $30 \mathrm{~min}$ to attain uniformity. ${ }^{18}$ The enteric coating solutions were prepared in different concentrations like 20\%,25\% and $30 \%$ of coating (Table 4). Enteric coating dispersion

\begin{tabular}{|c|c|c|c|}
\hline \multicolumn{4}{|c|}{ Table 4: Formulation for enteric coating solution. } \\
\hline & Batch 1(20\%) & Batch 2(25\%) & Batch 3(30\%) \\
\hline Ingredients & Mg/tab & Mg/tab & Mg/tab \\
\hline HPMC AS MF & 25.20 & 31.5 & 37.80 \\
\hline Triethyl citrate & 7.05 & 8.82 & 10.58 \\
\hline SLS & 0.75 & 0.94 & 1.12 \\
\hline Talc UM & 9.00 & 11.25 & 13.50 \\
\hline $\mathrm{NH}_{3}$ & $\begin{array}{c}\text { NA } \\
\text { (Qs to pH-7-9) }\end{array}$ & $\begin{array}{c}\text { NA } \\
\text { (Qs to pH-7-9) }\end{array}$ & $\begin{array}{c}\text { NA } \\
\text { (Qs to pH-7-9) }\end{array}$ \\
\hline Opadry brown & 6.30 & 7.88 & 9.46 \\
\hline
\end{tabular}

\begin{tabular}{|c|c|c|}
\hline \multicolumn{3}{|c|}{ Table 5: Parameters of coating. } \\
\hline SI. No. & Parameters & Data \\
\hline 1 & Inlet Temperature $\left({ }^{\circ} \mathrm{C}\right)$ & $43-47$ \\
\hline 2 & Exhaust Temperature $\left({ }^{\circ} \mathrm{C}\right)$ & $39-41$ \\
\hline 3 & Bed Temperature $\left({ }^{\circ} \mathrm{C}\right)$ & $38-41$ \\
\hline 4 & Pan RPM & $10-13$ \\
\hline 5 & Spray Pump RPM & $3-5$ \\
\hline 6 & Atomization & $1.2-1.6$ bar \\
\hline
\end{tabular}

was sprayed onto pre warmed sub coated tablets with following parameters mentioned in Table 5.

\section{Evaluation of coated tablets}

Formulated Omeprazole enterric coated tablets were evaluated (as per USP) for the weight variation, hardness, friability and disintigration time. The formulations were assessed by dissolution testing. Initial dissolution study was administered by USP type II Paddle (Electro $\mathrm{Lab}$ ) at $100 \mathrm{rpm}$ in $750 \mathrm{ml}$ of $0.1 \mathrm{~N} \mathrm{HCl}$ for $120 \mathrm{~min}$ and later in $900 \mathrm{ml}$ of $\mathrm{pH} 6.8$ acetate buffer for hour.

\section{Instrumental characterization}

\section{Powder X-Ray diffraction(XRD)}

The X-ray powder diffraction (XPRD) pattern of omeprazole and with other excipients were analysed utilizing a Rigaku (Ultima-IV) diffractometer. It shows 


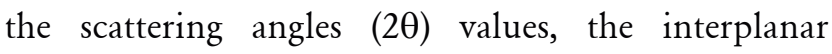
d-spacing $\left(\mathrm{A}^{\circ}\right)$, observed for the major diffraction peaks. The angular range was within $5^{\circ}$ to $60^{\circ}(2 \theta)$.

\section{Differential scanning calorimetry (DSC)}

Differential scanning calorimetry studies were performed for the drug and excipients utilizing a Mettler Toledo DSC-1 Stare system (Mettler Toledo) underneath the subsequent conditions: sample weight 3-5 $\mathrm{mg}$, scanning speed $10^{\circ} \mathrm{C} / \mathrm{min}$, within the $25-200^{\circ} \mathrm{C}$ temperature range. The samples were heated in hermetically sealed aluminum pans and indium was utilised as standard (Brittain, 2010).

\section{Fourier transform infrared (FTIR) spectroscopic}

The infrared (IR) absorption spectrum of omeprazole and other excipients were obtained in a $\mathrm{KBr}$ pellet using a Jasco (FT/IR-4600) IR spectrophotometer.

\section{RESULTS AND DISCUSSION}

\section{Evaluation of core tablets}

The physicochemical charecters under evaluation for both core and coated tablets were found to be compliant to USP guidelines for the said concern. Different parameters such as hardness, thickness, strength and weight variation were evaluated. For core tablets thickness of all tablets ranges between 3.21 to $3.28 \mathrm{~mm}$ and hardness was found within the vary of 5.10 to $5.82 \mathrm{KP}$. Percentage weight loss for all the batches was less than 1 chronicles in the fibrillation apparatus. It has been found from the weight variation and drug content analysis that all the formulations were within permissible USP range (average weight- $229 \mathrm{mg}$ to $235 \mathrm{mg}$ and individual weight- $227 \mathrm{mg}$ to $235 \mathrm{mg}$ ). Disintegration time of core tablets were found to be within $5 \mathrm{~min} 30 \mathrm{sec}$ to $6 \mathrm{~min} 10 \mathrm{sec}$. which is in compliance with the USP.

\section{Drug release study}

The drug release of all formulations i.e. Batch one (20\%), Batch $2(25 \%)$ and Batch $3(30 \%)$ of enteric coated tablets was carried out in $0.1 \mathrm{~N} \mathrm{HCl}$ for two hours and one hour in acetate buffer $\mathrm{pH}$ 6.8. ${ }^{19}$

\section{Acid resistance}

All the three batches (1,2 and 3) were observed in acidic medium i.e. $0.1 \mathrm{~N} \mathrm{HCl}$. In Batch 1 demonstrated degradation upto $87 \%$ for all the tablets and failed to adher USP specifications. In Batch 2 and 3 all the tablets degraded were in the range of $0.8 \%$ and $0.3 \%$ respec- tively. Further characterization was carried out on batch 2 and 3 .

\section{Drug release profile}

The dissolution study was done in $\mathrm{pH} 6.8$ acetate buffer $900 \mathrm{ml}$ for $1 \mathrm{hr}$. The dissolution profiles of batch 2 and 3 were displayed in Figure 1. In this Figure the batch 3 drug release is slower compared to batch 2 due to excess concentration of enteric coating polymer and other excipients coated during enteric coating. As per USP guidelines for the enteric coated tablets, for immediate release formulations the drug release in $\mathrm{pH} 6.8$ acetate buffer should be more than $80 \%$ in $10 \mathrm{~min}$. In $\mathrm{pH} 6.8$ acetate buffer all the enteric coated tablets behaved like immediate release formulation. Basing on the release profile batch 2 was selected for further stability studies. Kinetic modeling approach has been applied to the dissolution data to understand the underlying mechanism. Zero order, first order, Higuchi, Hixson Crowell and Korsmeyer Pappas equation models were tried. ${ }^{20}$ Selection of best fit was made on the basis of highest regression coefficient $\left(\mathrm{r}^{2}\right)$ value depicted in Table 6 . The correlation coefficient value for peppas model were found to be highest. Peppas kinetic release exponent value (n) was more than 0.5 and less than 1 for both the trials,which indicates that the drug release is both diffusion and erosion dependent.

\section{Stability study}

Batch 2 was selected for the stability studies. The omeprazole tablets were packed in two different type of packaging i.e. alu-alu blister and HDPE bottle. The packed tablets were subjected to accelerated stability

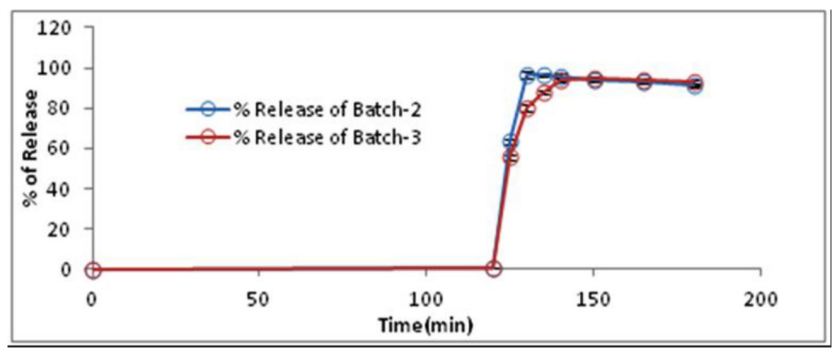

Figure 1: Dissolution profile of Batch 2 and Batch 3.

Table 6: Kinetics of in-vitro drug release.

\begin{tabular}{|c|c|c|c|c|c|}
\hline & $\begin{array}{c}\text { Zero } \\
\text { order }\end{array}$ & $\begin{array}{c}\text { First } \\
\text { order }\end{array}$ & Higuchi & \multicolumn{2}{|c|}{ Peppas } \\
\hline Batch & $\mathbf{r}^{\mathbf{2}}$ & $\mathbf{r}^{\mathbf{2}}$ & $\mathbf{r}^{\mathbf{2}}$ & $\mathbf{r}^{\mathbf{2}}$ & $\mathbf{n}$ \\
\hline Batch -2 & 0.5546 & 0.5142 & 0.5052 & 0.9241 & 0.5394 \\
\hline Batch -3 & 0.5861 & 0.5656 & 0.5101 & 0.9248 & 0.5302 \\
\hline
\end{tabular}


testing $\left(40^{\circ} \mathrm{C} / 75 \% \mathrm{RH}\right)$ for 3 months. After the study period the tablet showed no physical changes in their appearance. Acid resistance and the dissolution study was carried out for stability charged batches (Table 7).

\section{Acid resistance}

The acid degradation of tablets charged in alu-alu blister packaging and HDPE packaging were found to be $2.1 \%$ and $1.9 \%$ respectively. According to USP guidelines the degradation should not be more than $10 \%$, so the two batches passed as per USP monograph.

\section{Dissolution (6.8 acetate buffer-900 ml/paddle-100 RPM/1 hr)}

After $2 \mathrm{hr}$ of acid resistance all the tablets were transferred into $\mathrm{pH} 6.8$ acetate buffer and was observed for 1 hr. Drug release of the Stability batches remained same as that of Batch 2 (Figure 2).

\section{Powder X-Ray diffraction (XRD)}

The diffractogram of the pure omeprazole showed the typical peaks appearing at 10.6, 12.34, 19.80, 23.93 and $27.62(2 \theta)$ (Figure 3). ${ }^{21}$ The high intensity pointed peaks of omeprazole pure drug established its inherent crystallinity. The diffractogram of physical mixtures corresponding to Omeprazole, HPMC AS, HPMC E 5, Lactose, SSG, SSF, Talc, PEG6000 and SLS depicted in Figure 3 potrayed lower intensity peaks due to the presence of polymers. The diffractogram of omeprazole

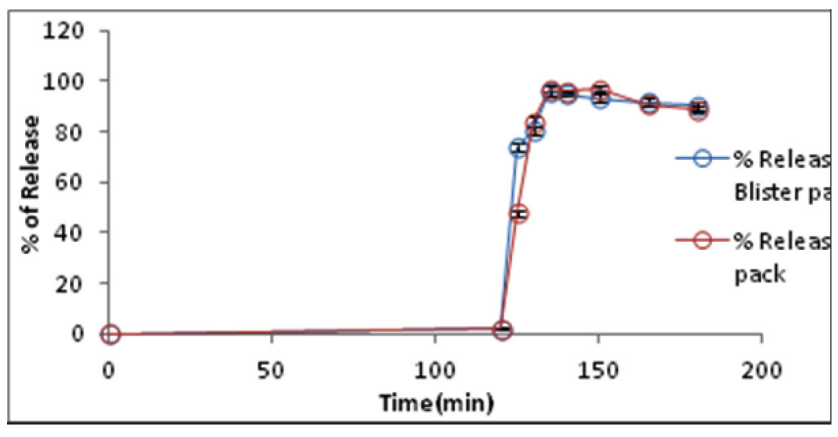

Figure 2: Dissolution profile of omeprazole delayed release tablet after loaded at $40^{\circ} \mathrm{C} / 75 \% \mathrm{RH}$ in stability chamber.

\begin{tabular}{|c|c|c|c|c|c|}
\hline \multicolumn{6}{|c|}{ Table 7: Kinetics of in-vitro drug release of stability } \\
charged batches. \\
\hline & $\begin{array}{c}\text { Zero } \\
\text { order }\end{array}$ & $\begin{array}{c}\text { First } \\
\text { order }\end{array}$ & Higuchi & \multicolumn{2}{|c|}{ Peppas } \\
\hline Batch & $r^{2}$ & $r^{2}$ & $r^{2}$ & $r^{2}$ & $n$ \\
\hline $\begin{array}{c}\text { Alu-Alu } \\
\text { package }\end{array}$ & 0.5805 & 0.5618 & 0.5302 & 0.9355 & 0.5377 \\
\hline $\begin{array}{c}\text { HDPE } \\
\text { package }\end{array}$ & 0.5584 & 0.4982 & 0.4932 & 0.9066 & 0.5299 \\
\hline
\end{tabular}

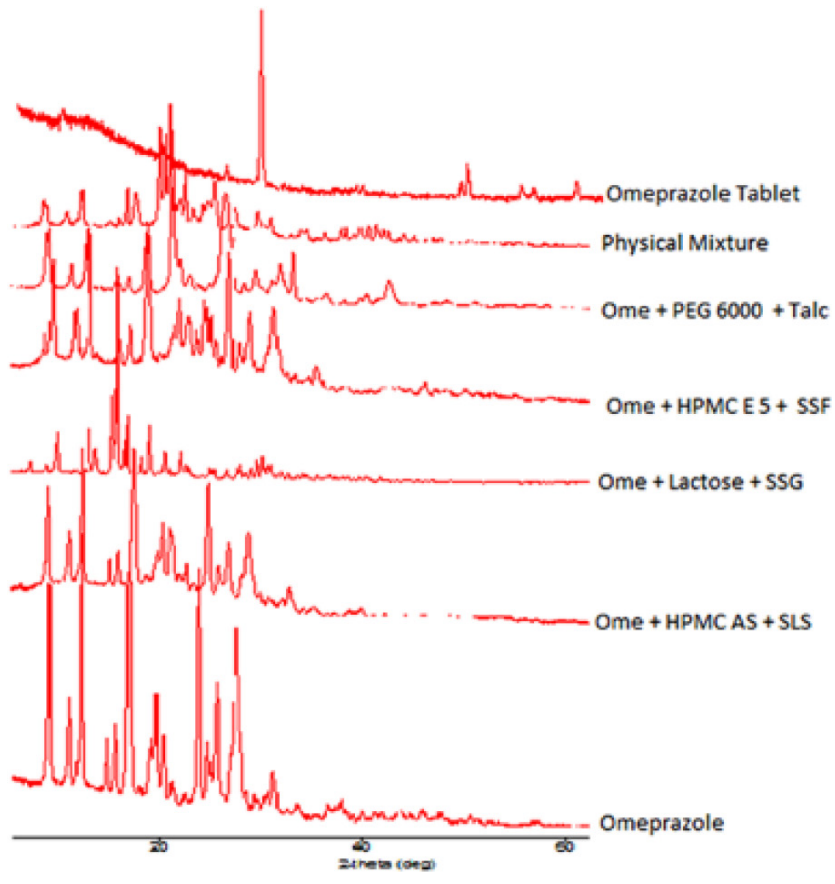

Figure 3: XRD pattern of omeprazole, drug polymer physical mixtures and Tablet.

tablet showed only one characteristic intensity peaks appearing at $29.31(2 \theta)$. The intensity of characteristic peaks of omeprazole has been lowered substantially in the tablet formulation. The increase of the full width at half maximum (FWHM) in the diffraction pattern of the formulation was may be the result of possible conversion of microstate of crystalline drug to amorphous form.

\section{Differential scanning calorimetry (DSC)}

The DSC thermogram was employed for the derivation and characterization melting point and crystalline behaviour of the drug. ${ }^{22}$ DSC thermogram of pure omeprazole revealed a charecterstics endothermic peak with sharp melting point at $159^{\circ} \mathrm{C}$, which confirmed its crystalline characteristics. The endothermic peaks of physical mixtures containing omeprazole and polymers (HPMC AS, HPMC E 5, SSG, SSF, SLS, Lactose, Talc and PEG 6000) depicted in Figure 4 shows lowering in intensity and shifting of endothermic peaks as compared to the pure drug. In case of tablet, the endothermic peak of omeprazole was found to be $143.46^{\circ} \mathrm{C}$. The shifting of peaks are the outcomes of the dispersion of crystalline drug entity in the polymeric matrix.

\section{Fourier transform infrared (FTIR) spectroscopy Analysis.}

An overlay of FTIR spectra of the pure omeprazole, drug polymer physical mixtures and tablets with spectral 


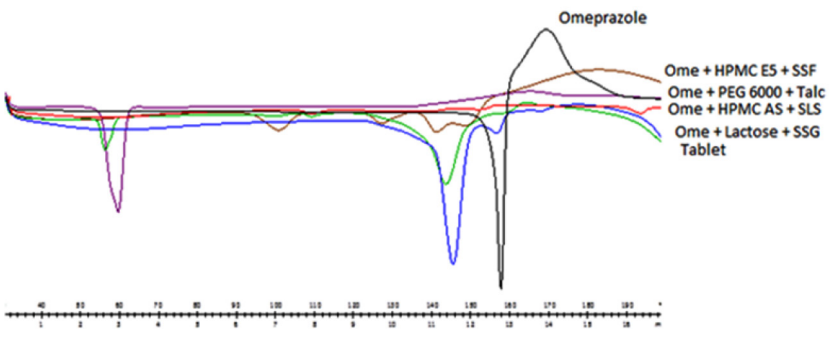

Figure 4: DSC thermogram of omeprazole, drug polymer physical mixtures and Tablet.

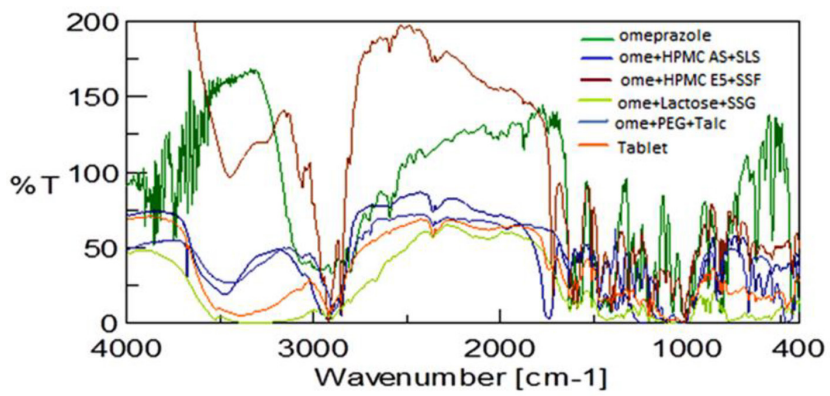

Figure 5: FTIR spectra of omeprazole, drug polymer physical mixtures and Tablet.

shifts were depicted in Figure 5. Spectra of pure omeprazole potrayed characteristics band at $2902.34 \mathrm{~cm}^{-1}$, $1627.60 \mathrm{~cm}^{-1}, 1586.16 \mathrm{~cm}^{-1}, 1158.01 \mathrm{~cm}^{-1}$ and 1074.16 $\mathrm{cm}^{-1}$ due to $\mathrm{C}-\mathrm{H}$ stretch, $\mathrm{C}=\mathrm{C}$ stretch, $\mathrm{C}=\mathrm{N}$ stretch, $\mathrm{CH}_{2}$ stretch, $\mathrm{C}=\mathrm{O}$ stretch and $\mathrm{C}=\mathrm{S}$ stretch respectively. Spectra of characteristics peaks band at $\left(1407.78 \mathrm{~cm}^{-1}\right.$, $\left.1310.39 \mathrm{~cm}^{-1}\right)$ is due to $\mathrm{CH}$ bending and $1510.95 \mathrm{~cm}^{-1}$ due to $\mathrm{CH}_{2}$ bending respectively. Peak bands at $965.19 \mathrm{~cm}^{-1}, 885.166 \mathrm{~cm}^{-1}, 822.49 \mathrm{~cm}^{-1}$ is also due to $\mathrm{C}-\mathrm{H}$ bending. In the tablet formulation, characterisics peaks corresponding to pure omeprazole overlapped to form strong asymmetric envelope assembled arround $822.49 \mathrm{~cm}^{-1}$ to $1627.60 \mathrm{~cm}^{-1}$. The characteristics peaks were broad as compared to omeprazole pure drug. In this region all the formulation Frequency of stretching and bending were either shifted or masked due to the drug-excipients interaction i.e. intramolecular hydrogen bonding.

\section{CONCLUSION}

All the batches (1, 2 and 3) of omeprazole delayed release tablet were observed in dissolution media. It was found that the batch 2 and 3 had resisted acidic medium for $2 \mathrm{hr}$ and got released in $\mathrm{pH} 6.8$ acetate buffer due to maximum concentration of enteric coating polymer, other excipients used and the smaller diffusion pore size. The release of omeprazole from batch $2(97 \%)$ was significantly high as compared to batch
$3(76 \%)$ due to the abundancy of enteric coating polymer. Instrumental characterization such as FTIR, DSC and XRD revealed that the crystalline drug has been amorphised in the tablet formulation.

\section{ACKNOWLEDGEMENT}

The authors are very much grateful to Prof. Manoj Ranjan Nayak, President, Siksha 'O' Anusandhan (Deemed to be University) for his inspirations and facilities.

\section{CONFLICT OF INTEREST}

The authors declare no conflict of interest.

\section{ABBREVIATIONS}

HPMC: Hydroxylpropylmethycellulose; FTIR: Fourier transform infrared spectroscopy; SEM: Scanning electron microscopy; DSC: Differential Scanning Calorimeter; PPI: Proton Pump Inhibitor.

\section{REFERENCES}

1. Kato I, Nomura AM, Stemmermann GN, Chyou PH. A prospective study of gastric and duodenal ulcer and its relation to smoking, alcohol, and diet. Am J Epidemiol. 1992 Mar 1;135(5):521-30. doi: 10.1093/oxfordjournals.aje. a116319, PMID 1570818.

2. Oustamanolakis P, Tack J. Dyspepsia: organic versus functional. J Clin Gastroenterol. 2012 Mar 1;46(3):175-90. doi: 10.1097/ MCG.0b013e318241b335, PMID 22327302.

3. Howden CW. Clinical pharmacology of omeprazole. Clin Pharmacokinet. 1991 Jan;20(1):38-49. doi: 10.2165/00003088-199120010-00003, PMID 2029801.

4. Farinha A, Bica A, Martins JM, Pais JP. Dissolution of omeprazole from delayed-release solid oral dosage forms. Drug Dev Ind Pharm. 2000 Jan 1;26(7):785-90. doi: 10.1081/ddc-100101300, PMID 10872100.

5. Puscas I, Coltau M, Baican M, Domuta G. Omeprazole has a dual mechanism of action: it inhibits both $\mathrm{H}+\mathrm{K}+$ ATPase and gastric mucosa carbonic anhydrase enzyme in humans (in vitro and in vivo experiments). J Pharmacol Exp Ther. 1999 Aug 1;290(2):530-4.

6. Lindberg $P$, Nordberg $P$, Alminger T, Brändström A, Wallmark B. The mechanism of action of the gastric acid secretion inhibitor omeprazole. J Med Chem. 1986;29(8):1327-9. doi: 10.1021/jm00158a001. PMID 3016260.

7. Badillo R, Francis D. Diagnosis and treatment of gastroesophageal reflux disease. World J Gastrointest Pharmacol Ther. 2014 Aug 6;5(3):105-12. doi: 10.4292/wjgpt.v5.i3.105, PMID 25133039.

8. Kaplan EL, Tanaka R, Ito K, Younes N, Friesen SR. The discovery of the Zollinger-Ellison syndrome. J Hep Bil Pancr Surg. 1994 Oct 1;1(5):509-16. doi: 10.1007/BF01211912.

9. Acharya M, Mishra S, Sahoo RN, Mallick S. Infrared spectroscopy for analysis of co-processed ibuprofen and magnesium trisilicate at milling and freeze drying. Acta Chim Slov. 2017 Mar 1;64(1):45-54. doi: 10.17344/ acsi.2016.2772, PMID 28380218.

10. Yang R, Schulman SG, Zavala PJ. Acid-base chemistry of omeprazole in aqueous solutions. Anal chim acta. 2003 Mar 28;481(1):155-64. doi: 10.1016/ S0003-2670(03)00076-X.

11. Ozturk SS, Palsson BO, Donohoe B, Dressman JB. Kinetics of release from enteric-coated tablets. Pharm Res. 1988;5(9):550-65. doi: 10.1023/a:1015937912504, PMID 3247318. 
12. Deshpande TM, Quadir A, Obara S, Ibrahim A, Hoag SW. Developing a stable aqueous enteric coating formulation with hydroxypropyl methylcellulose acetate succinate (HPMCAS-MF) and colloidal silicon dioxide as antitacking agent. Int J Pharm. 2018 May 5;542(1-2):108-16. doi: 10.1016/j. ijpharm.2018.02.025, PMID 29458205.

13. Choi HG, Jung JH, Yong CS, Rhee CD, Lee MK, Han JH, Park KM, Kim CK. Formulation and in vivo evaluation of omeprazole buccal adhesive tablet. J Control Release. 2000 Sep 3;68(3):405-12. doi: 10.1016/s01683659(00)00275-3, PMID 10974394

14. Turkoglu M, Varol H, Elikok M. Eur J Pharm Biopharm. Tableting and stability evaluation of enteric-coated omeprazole pellets. 2004;57(2):279-86.

15. Choudhury A, Das S, Bahadur S, Saha S, Roy A. Formulation and evaluation of omeprazole tablets for duodenal ulcer. Indian J Pharm Sci. 2010;72(4):4914. doi: 10.4103/0250-474X.73922, PMID 21218061.

16. Tanno F, Nishiyama $Y$, Kokubo H, Obara S. Evaluation of hypromellose acetate succinate (HPMCAS) as a carrier in solid dispersions. Drug Dev Ind Pharm. 2004;30(1):9-17. doi: 10.1081/ddc-120027506, PMID 15000425.

17. Czarnocka JK, Alhnan MA. Gastro-resistant characteristics of GRAS-grade enteric coatings for pharmaceutical and nutraceutical products. Int J Pharm. 2015;486(1-2):167-74. doi: 10.1016/j.jpharm.2015.03.039, PMID 25796126.
18. Deshpande TM, Quadir A, Obara S, Ibrahim A, Hoag SW. Developing a stable aqueous enteric coating formulation with hydroxypropyl methylcellulose acetate succinate (HPMCAS-MF) and colloidal silicon dioxide as antitacking agent. Int J Pharm. 2018;542(1-2):108-16. doi: 10.1016/j. ijpharm.2018.02.025, PMID 29458205.

19. Liu F, Shokrollahi H. In vitro dissolution of proton-pump inhibitor products intended for paediatric and geriatric use in physiological bicarbonate buffer. Int J Pharm. 2015;485(1-2):152-9. doi: 10.1016/j.ijpharm.2015.03.008, PMID 25746736.

20. Dash S, Murthy PN, Nath L, Chowdhury P. Kinetic modeling on drug release from controlled drug delivery systems. Acta Pol Pharm. 2010;67(3):217-23. PMID 20524422.

21. El-Badry M. Comparative study of preparation and characterization of enteric and enhanced release omeprazole microparticles. J Drug Deliv Sci Technol. 2011;21(6):491-6. doi: 10.1016/S1773-2247(11)50079-6.

22. Sahoo RN, De A, Kataria V, Mallick S. Solvent-free hot melt extrusion technique in improving mesalamine release for better management of inflammatory bowel disease. Indian J Pharm Educ Res. 2019;53(4s):s554-62.

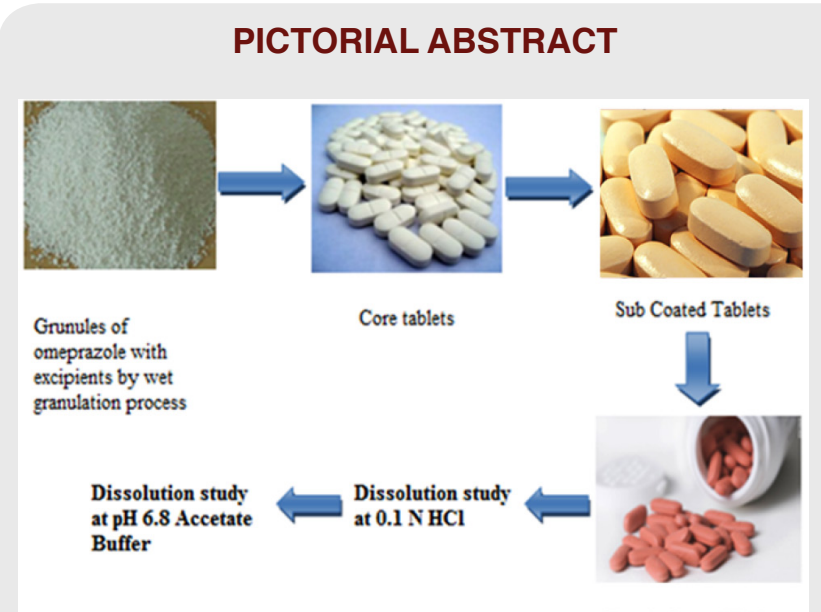

Enteric Coated Tablets

\section{SUMMARY}

In recent years omeprazole has been extensively used for inhibition of acid secretion in stomach. Omeprazole is available in various types of dosage forms namely, pellets, capsule, suspension and injection. These kind of preparations generally suffers from disadvantages like difficulty in administration and stability. To overcome the above mentioned lacuna omeprazole tablets were prepared for easy oral administration. The inherent poor flow property of omeprazole was addressed by carrying out wet granulation using HPMC E5 LV as binder. Omeprazole gets degraded in the stomach; to prevent this enteric coating was done employing HPMC. This formulatory approach can be transferred to local pharmaceutical industries.

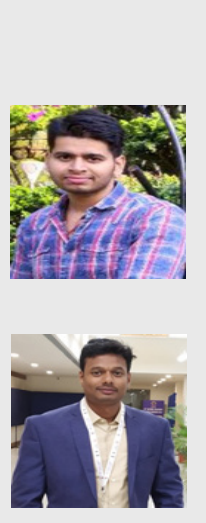

\begin{abstract}
About Authors
Sagar Kumar Mohapatra, M.Pharm from Siksha 'O' Anusandhan (Deemed to University), Bhubaneswar, Odisha, India.

Rudra Narayan Sahoo, M.Pharm, Assistant Professor at Centurion University of Technology and Management, Bhubaneswar, Odisha, India. Continuing PhD at Siksha'O' Anusandhan (Deemed to be University), Bhubaneswar, India. His research area of interest is Formulation and Development, and Drug Delivery Systems.
\end{abstract}


Subrata Mallick (MPharm, PhD, PGDBM, FIC) is a life member of Association of Pharmaceutical Teachers of India, and Indian Pharmaceutical Association. At present he is the Professor and Heading the Department of Pharmaceutics, School of Pharmaceutical Sciences, Siksha'O' Anusandhan (Deemed to be University), Bhubaneswar, India. He is the reviewer of Elsevier, Wiley, Informa Healthcare, Taylor and Francis, Bentham Science, Springer, IEEE Xplore, Dovepress etc. and editorial board member of several International Journals of America, Canada, UK, Thailand, India etc. He is also a member of doctoral committee of several universities. His current research areas of interest are: Ocular Drug Delivery Systems, Drug Stabilisation and Kinetics, Mucosal Delivey, Powder Compaction etc. More than 160 number of full research papers and conference proceedings are published in International and National levels under his guidance.

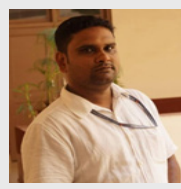

Rajaram Mohapatra, M.Pharm, PhD, At present he is the Assistant Professor Department of Pharmaceutics, School of Pharmaceutical Sciences, Siksha'O' Anusandhan (Deemed to be University), Bhubaneswar, India. His current research areas of interest are: controlled Drug Delivery Systems using natural gum, Drug Stabilization and Kinetics, Mucosal Delivey, Powder Compaction etc.

Cite this article: Mohapatra SK, Sahoo RN, Mallick S, Mohapatra R. Enteric Dissolution Enhancement of Engineered Gastro Resistant Omeprazole Tablets using Hydroxypropyl Methylcellulose Acetate Succinate. Indian J of Pharmaceutical Education and Research. 2021;55(3):677-84. 